Научная статья

Удк 347.1

DOI https://doi.org/10.24866/VVSU/2073-3984/2021-4/148-155

М.В. Вронская ${ }^{1}$

Владивостокский государственный университет экономики и сервиса

Владивосток. Россия

Е.О. Василенко ${ }^{2}$

Общество с ограниченной ответственностью «Порт «Вера»

Владивосток. Россия

\title{
Назначение и функции презумпции добросовестности участников предпринимательских правоотношений
}

\begin{abstract}
Аннотация. В статье приведены нормы права, акты толкования и правовая доктрина, раскрывающие понятие, сущность и назначение презумпции добросовестности, закреплённой в статье 10 Гражданского кодекса РФ. Раскрыт идейный смысл законодательного закрепления презумпции добросовестности. Приведены примеры юридико-технического и юридико-практического значения презумпции. Рассмотрено, каким образом данная правовая категория оказывает влияние на субъектов предпринимательских правоотношений. Проанализировав правовые нормы, содержащие дефиницию “добросовестность» в контексте корпоративных отношений, авторы раскрывают подходы к пониманию категории "добросовестность», а также функции одной из ключевых презумпций гражданского законодательства. В частности, проанализированы и проиллюстрированы примерами процессуальная и охранительная функции. Приведен пример, когда презумпция может служить способом восполнения пробелов права, а также сделаны выводы относительно релевантности презумпции с учетом участившихся случаев злоупотребления правом участниками предпринимательских правоотношений.
\end{abstract}

Ключевые слова: правовая презумпция, добросовестность, злоупотребление правом, предпринимательские правоотношения, индивидуальные предприниматели, участники хозяйственных обществ.

1 Вронская Мария Владимировна - канд. юрид. наук, доцент кафедры ГПД, Институт права. ORCID: https://orcid.org/0000-0001-5942-1158; e-mail: m.vronskaya@mail.ru

2 Василенко Екатерина Олеговна - бакалавр, помощник юрисконсульта; e-mail: ekaterinavasilenko@list.ru 
M.V. Vronskaya

Vladivostok State University of Economics and Service

Vladivostok. Russia

E.O. Vasilenko

Limited liability company «Port «Vera»

Vladivostok. Russia

\title{
The concept and functions of the presumption of good faith of participants in entrepreneurial legal relations
}

\begin{abstract}
The article contains the norms of law, acts of interpretation and legal doctrine that reveal the concept, essence and purpose of the presumption of good faith, enshrined in article 10 of the Civil Code of the Russian Federation. The ideological meaning of legislative consolidation of the presumption of good faith is revealed. Examples of legal-technical and legal-practical significance of the presumption are given. It is considered how this legal category affects the subjects of entrepreneurial legal relations. Having analyzed the legal norms containing the definition of "good faith" in the context of corporate relations, the authors reveal approaches to understanding the category of "good faith», as well as the functions of one of the key presumptions of civil law. In particular, procedural and protective functions are analyzed and illustrated with examples. An example is given when a presumption can serve as a way to fill gaps in law. And also conclusions were made regarding the relevance of the presumption, taking into account the increasing cases of abuse of the right by participants in entrepreneurial legal relations.
\end{abstract}

Keywords: legal presumption, good faith, abuse of law, business legal relations, individual entrepreneurs, participants in business companies.

\section{Введение}

В 2013 году в статье 10 Гражданского кодекса появилась формулировка: «добросовестность участников гражданских правоотношений и разумность их действий предполагаются» [1]. Данная правовая норма является презумпцией добросовестности, которая по определению заведомо наделяет субъектов правоотношений добросовестностью до тех пор, пока не будет доказано обратное. Законодательного закрепления дефиниции «добросовестность» закон не содержит, однако все правоведы сходятся во мнении, что данное понятие подразумевает требование законодателя к участникам гражданского оборота соблюдать правовые нормы и действовать в пределах осуществления гражданских прав, не прибегая к злоупотреблению.

Юристы, исследующие правовую природу презумпции добросовестности и проблематику злоупотребления правом, отмечают некорректность правовых норм, содержащихся в Гражданском кодексе, отсутствие обобщенной судебной практики по данному вопросу, а также наличие в специальных законах большого количества диспозитивных норм, позволяющих индивидуальным предпринимателям и участникам юридических лиц трактовать закон так, как выгодно им, с нарушением принципа добросовестности. В данной статье остановимся на таких 
участниках гражданского оборота, как субъекты предпринимательских правоотношений, чтобы рассмотреть, какое влияние оказывает на них презумпция добросовестности. Целью работы является рассмотрение подходов к сущности вышеуказанной презумпции, выяснение целей, которые преследовал законодатель, закрепляя её в статье 10 ГК РФ, а также анализ функционального назначения презумпции добросовестности в контексте реализации её в предпринимательских правоотношениях.

В статье были использованы такие методы научного исследования, как анализ и синтез, индукция и дедукция, а также формально-юридический метод, анализ и обобщение правовых материалов, правовое прогнозирование.

\section{Основная часть}

Субъекты предпринимательской деятельности - это и индивидуальные предприниматели, и юридические лица, которые в качестве основной цели осуществления деятельности выделяют получение прибыли. К коммерческим формам юридических лиц можно отнести: хозяйственные общества, товарищества и партнерства, производственные кооперативы, государственные и муниципальные унитарные предприятия и крестьянские (фермерские) хозяйства. Безусловно, самыми распространёнными организационно-правовыми формами являются хозяйственные общества, которые представляют собой общества с ограниченной ответственностью и акционерные общества. На них и будет сделан акцент в данной работе.

Наряду с презумпцией, закреплённой в статье 10 Гражданского кодекса РФ, данное понятие упоминается в качестве принципа еще в нескольких правовых нормах. Так, например, статья 53 Гражданского кодекса, которая посвящена органам юридических лиц, в пункте 3 предписывает, что лицо, уполномоченное выступать от имени юридического лица, осуществляя представительство, обязано действовать в интересах организации добросовестно и разумно [1].

В статье 53.1 Гражданского кодекса законодатель наделяет участников юридических лиц, которые фактически способны своими решениями определять действия юридического лица, в том числе за убытки, причиненные организации по его вине, ответственностью. Вместе с тем в пункте 3 законодатель предписывает соответствующим субъектам действовать добросовестно. Необходимо подчеркнуть, что в данной норме права дефиниции «добросовестность» и «недобросовестность» в общей сложности фигурируют пять раз.

Аналогичную норму права, содержащую принцип добросовестности, можно встретить в статье 44 Федерального закона № 14-Ф3 [2]. Норма права, раскрывая понятие и содержание ответственности высших органов управления общества с ограниченной ответственностью, также говорит о том, что члены совета директоров и иные органы при осуществлении своих прав и реализации обязанностей должны действовать добросовестно.

Почти идентичная по содержанию норма права содержится и в Федеральном законе № 208-Ф3 [3]. Пункт 1 статьи 71, перечисляя все исполнительные органы акционерных обществ, предписывает, что в отношении общества каждый из них обязан действовать в рамках принципа добросовестности. 
М.В. Вронская, Е.О. Василенко. Назначение и функции презумпции добросовестности...

В 2013 году Постановление Пленума Высшего Арбитражного Суда РФ предприняло попытку внести ясность в порядок возмещения убытков, причиненных юридическому лицу в результате действий физических лиц, входящих или входивших ранее в его состав [4, с. 14]. В пункте 1 данного Постановления указано: поскольку предпринимательская деятельность характеризуется риском, сам факт причинения убытков членом юридического лица не свидетельствует о нарушении принципа недобросовестности. Кроме того, тот же пункт предписывает, что в случае, когда директор не выходил за рамки предпринимательского риска, а равно действовал добросовестно, он не может быть привлечен к ответственности за причинённые организации убытки.

Кроме того, в Постановлении указано, что именно истец должен доказать факт недобросовестности лица, по вине которого юридическому лицу были причинены убытки, что опять же отсылает нас к презумпции добросовестности, закреплённой в статье 10 Гражданского кодекса РФ. Директор общества не должен, но может представить доказательства того, что на момент совершения правонарушения квалификация действий юридического лица не являлась очевидной; помимо этого директор вправе ссылаться на отсутствие единообразия судебной практики по отдельно взятому вопросу. В то же время, если судом будет установлено, что директор уклоняется от пояснений или представляет неполные доказательства относительно того, каким образом возникли убытки, суд вправе признать его недобросовестным; в таком случае суд вправе возложить бремя доказывания на директора, то есть ответчика.

Высший Арбитражный Суд РФ впервые предпринял попытку раскрыть понятие добросовестности, однако он исходил из того, что «добросовестность» и «разумность» являются смежными понятиями, а потому суд даёт обобщённую характеристику двум принципам, не раскрывая каждый по отдельности. Так, сущность добросовестности и разумности при исполнении директором хозяйственного общества своих должностных обязанностей заключается в том, чтобы достичь целей, ради которых юридическое лицо было создано в рамках обычаев предпринимательского риска. Кроме того, ряд авторов утверждает, что принцип добросовестности является общим по отношению к двум другим основополагающим принципам - справедливости и разумности, и рассматривать их необходимо исключительно в совокупности [5, с. 122].

Стоит отметить, что ни один из вышеперечисленных нормативно-правовых актов и актов толкования не содержит развёрнутого перечня критериев добросовестности участников юридического лица, что, безусловно, является пробелом законодательства и может приводить к отсутствию единообразия в практике применения статьи 10 Гражданского кодекса.

Проанализировав правовые нормы, содержащие дефиницию «добросовестность» в контексте корпоративных отношений, можно отметить, что принцип добросовестности и соответствующая презумпция применяются в отношении лиц, выступающих от имени юридического лица, особенно данные положения распространяются на директора и органы управления хозяйственного общества. Соблюдение данного принципа предполагает, что единоличный или коллеги- 
альный орган обязан действовать в соответствии с «доброй совестью» [6, с. 125]. Это значит, что лица, входящие в состав юридического лица, обязаны не только действовать в рамках правового поля, не выходя за пределы правовых предписаний, но и объективно оценивать каждую отдельно взятую ситуацию, отстаивая при этом интересы общества, должника и кредитора.

Существует два основных подхода к сущности добросовестности в корпоративных отношениях. Авторы, придерживающиеся первого подхода, рассматривают дефиницию «добросовестность» в качестве нравственно-этической категории. Применительно к предпринимательским отношениям это означает, что участники юридического лица должны признавать права и законные интересы контрагентов как свои собственные [7, с. 198]. Из данного положения следует, что участники организации, пренебрегающие правами и законными интересами другой стороны и ставящие в приоритет исключительно свои собственные цели, являются недобросовестными. В рамках данного подхода ряд авторов также отмечает, что участники корпорации обязаны в рамках принципа добросовестности заботиться не только о том, чтобы права и интересы контрагентов не были нарушены, но и заранее предвидеть и предотвращать угрозу нарушения, если таковая имеется [8, с. 140].

Второй подход к категории добросовестности участников предпринимательских отношений заключается в сочетании субъективного и объективного аспектов. Авторы данного подхода придерживаются точки зрения о том, что поведение любого субъекта корпорации при реализации прав и осуществлении обязанностей необходимо оценивать с двух сторон. Субъективный аспект поведения участника характеризуется внутренней оценкой лица, то есть такими понятиями, как честность, порядочность, старательность, и иными нравственно-этическими категориями. Одновременно с этим добросовестное поведение лица можно оценить с объективной стороны. В таком случае оценка осуществляется с позиции правового поля и обозначает невиновность лица, а также соответствие общепринятым правилам поведения и соблюдение границ предпринимательского обычая [9, с. 161].

Представляется правильным использовать данные подходы в синтезе, не выделяя какой-то один, так как само понятие «добросовестность» содержит как объективную, так и субъективную составляющую. Так, например, объективность заключается в процессе и способе реализации интересов организации, а субъективность можно проследить во внутренних детерминантах лица, непосредственно выполняющего определенные действия.

\section{Выводы}

Таким образом, хотелось бы отметить, что назначение презумпции добросовестности заключается в двух важных аспектах. Во-первых, юридикотехническое значение, при котором презумпция добросовестности носит регулятивный характер и является элементом, соединяющим нормы гражданского права между собой по смыслу, играет, таким образом, вспомогательную роль [10, c. 32]. Презумпция добросовестности также способна расширять или сужать объем норм права. Например, если лицо действовало добросовестно и к нему применима соответствующая презумпция, понятие гражданской ответственности, закрепленное в правовых нормах Гражданского кодекса, сужается. 
М.В. Вронская, Е.О. Василенко. Назначение и функции презумпции добросовестности...

Во-вторых, презумпция добросовестности выполняет юридико-практическое значение, заключающееся в том, чтобы сделать процесс доказывания проще. Законодатель снимает с лиц обязанность в подтверждении факта правомерности собственных действий и перекладывает её на другое лицо, считающее, что определенный субъект нарушил пределы осуществления гражданских прав. Таким образом, презумпция добросовестности помогает правильно распределить бремя доказывания, а если доказательств виновности лица недостаточно, позволяет беспроблемно разрешить вопрос о прекращении спора.

Ряд правоведов видит назначение презумпции добросовестности в способе ограничения свободы договора. Так, в результате недобросовестности одной из сторон правоотношения может быть заключен целый ряд сделок, которые позже будут признаны судом недействительными: кабальные сделки, сделки, заключенные под влиянием введения в заблуждение, обмана или угрозы, и сделки, совершенные за пределами полномочий лиц.

Говоря непосредственно о функциях, которые выполняет презумпция, можно выделить следующие.

Во-первых, презумпция добросовестности в предпринимательских отношениях может являться способом восполнения пробелов права, существующих в гражданском законодательстве [11, с. 300]. Так, если в правовом поле не обозначены какие-либо аспекты, например, по вопросу наделения участников корпораций ответственностью по поводу возмещения убытков, можно опираться на презумпцию, которая по определению заведомо наделяет субъектов таких отношений добросовестностью, что облегчает процесс гражданского оборота.

Во-вторых, презумпция добросовестности охраняет права и законные интересы субъектов предпринимательских отношений. Следовательно, в данном случае имеет место охранительная функция, которая защищает интерес коммерческой организации, позволяя её участникам действовать в рамках правового поля при реализации целей, ради которых данное юридическое лицо было создано. В частности, если юридическое лицо не нарушало нормы гражданского права, то его вина в суде будет доказана исключительно в случае опровержения презумпции (когда имело место злоупотребление правом или иная форма недобросовестного поведения участника предпринимательских правоотношений). Если же, наоборот, у суда отсутствуют сомнения в добросовестности субъекта, презумпция применяется, так как является достоверной, защищая тем самым юридическое лицо.

В-третьих, безусловно, одной из основных функций презумпции добросовестности в сфере предпринимательских правоотношений является процессуальная, поскольку необходимость в её непосредственном применении возникает после возникновения правового спора. Презумпция упрощает процесс доказывания, определяя регламент представления доказательств в гражданском процессе и возлагая бремя доказывания на истца, который считает, что его оппонент действовал недобросовестно.

Презумпция, кроме того, вносит ясность в весь гражданский оборот, заведомо наделяя субъектов определённым положительным признаком. Факт того, что участники отношений не обязаны ничем подтверждать свою честность, порядочность и другие нравственные качества своему оппоненту, опять же, упрощает правоотношения. 
Таким образом, идейный смысл законодательного закрепления презумпции добросовестности сводится к оценке поведения субъектов предпринимательских правоотношений не только с точки зрения правовых предписаний, но и с нравственно-этической стороны. Кроме того, нормы права, предписывающие участникам гражданского оборота действовать добросовестно, являются превентивной мерой, так как предупреждают субъектов, что в ответ на недобросовестное поведение могут наступить неблагоприятные последствия, а потому основная цель субъектов - не допустить злоупотребления правом и оставаться в рамках правового поля и в пределах осуществления гражданских прав. Таким образом, основная роль презумпции добросовестности сводится к регулированию правоотношений с оценкой поведения субъектов этих отношений на предмет нахождения в рамках осуществления гражданских прав.

1. Кирьянов А. Злоупотребление правом, добросовестность и разумность действий лиц при нарушении Закона «О рекламе» (на примере правоприменительной практики Орловского УФАС России) / под общ. ред. Е. В. Симоновой // Границы возможного в рекламном и PR-креативе: материалы Всероссийской (национальной) науч.-практ. конф. ОГУЭТ. - Орёл, 2018. - С. 31-34.

2. Знахуренко Д.К. Добросовестность (bona fides) в римском частном праве // Крымский академический вестник. - 2019. - Т. 8, № 11. - С. 56-59.

3. Остапович К.В. Научные исследования 2017: теоретическая часть: монография. - Москва: Русальянс, 2017. - 257 с.

4. Муртазакулов Д.С., Курбонов К.Ш. Принцип добросовестности в гражданском праве: предпосылки и основания появления // Власть закона. - 2017. - № 3 (31). - С. 157-182.

5. Гражданский кодекс Российской Федерации: части первая, вторая, третья и четвертая (+ сравнительная таблица): по состоянию на 03.02.2021. - Москва: Эксмо, 2021. - 930 с.

6. Вердиян Г. В. Реализация принципа добросовестности в современном гражданском праве // Правовая инициатива. - 2013. - Т. 1, № 10. - С. 11, 12.

7. Terdi E. Contractual preemptive rights: Russian doctrine and European tradition in the context of Russian civil code reform / E. Terdi, V. Velichko // Russian law journal. - 2019. Vol. 7, Is. 1. - P. 119-137. - URL: https://www.elibrary.ru/item.asp?id=44583854 (дата обращения: 04.05.2021).

8. Rusanov G. Perpetrators of corporate crimes in commercial organizations in Italy and Russia // Journal of financial crime. - 2020. - Vol. 28, Is. 1. - P. 120-130. - URL: https://clck.ru/VVSQJ (дата обращения: 04.05.2021).

9. Черкасова О. Становление принципа добросовестности в отечественном гражданском праве: исторический, доктринальный и правоприменительный аспекты. - Текст: электронный // Genesis: исторические исследования: [сайт]. - 2020. - № 2.- URL: https://cyberleninka.ru/article/n/stanovlenie-printsipa-dobrosovestnosti-v-otechestvennomgrazhdanskom-prave-istoricheskiy-doktrinalnyy-i-pravoprimenitelnyy-aspekty (дата обращения: 11.04.2021).

10. Соломин С. К. Принцип добросовестности: пределы реализации / под общ. ред. Д. Л. Цыбаковой // Гражданско-правовое регулирование общественных отношений в современной России: мат. 7-й междунар. научно-практической конференции. Среднерусский институт управления - филиал РАНХиГС. - Орёл, 2017. - С. 31-33.

11. Гражданско-правовое регулирование общественных отношений в современной России: сборник научных статей / под ред. Д. Л. Цыбаковой. - Орёл: Изд-во РАНХиГС, 2018. - Вып. 1. - 192 с. 


\section{Транслитерация}

1. Kir'yanov A. Zloupotreblenie pravom, dobrosovestnost' i razumnost' dejstvij lic pri narushenii Zakona «O reklame» (na primere pravoprimenitel'noj praktiki Orlovskogo UFAS Rossii) / pod obshch. red. E. V. Simonovoj // Granicy vozmozhnogo v reklamnom i PR-kreative: materialy Vserossijskoj (nacional'noj) nauch.-prakt. konf. OGUET. - Oryol, 2018. - S. 31-34.

2. Znahurenko D. K. Dobrosovestnost' (bona fides) v rimskom chastnom prave // Krymskij akademicheskij vestnik. - 2019. - T. 8, № 11. - S. 56-59.

3. Ostapovich K. V. Nauchnye issledovaniya 2017: teoreticheskaya chast': monografiya. Moskva: Rusal'yans, 2017. - 257 s.

4. Murtazakulov D.S., Kurbonov K. Sh. Princip dobrosovestnosti v grazhdanskom prave: predposylki i osnovaniya poyavleniya // Vlast' zakona. - 2017. - № 3 (31). - S. 157-182.

5. Grazhdanskij kodeks Rossijskoj Federacii: chasti pervaya, vtoraya, tret'ya i chetvertaya (+ sravnitel'naya tablica): po sostoyaniyu na 03.02.2021. - Moskva: Eksmo, 2021. - $930 \mathrm{~s}$.

6. Verdiyan G. V. Realizaciya principa dobrosovestnosti v sovremennom grazhdanskom prave // Pravovaya iniciativa. - 2013. - T. 1, № 10. - S. 11, 12.

7. Cherkasova O. Stanovlenie principa dobrosovestnosti v otechestvennom grazhdanskom prave: istoricheskij, doktrinal'nyj i pravoprimenitel'nyj aspekty. - Tekst: elektronnyj // Genesis: istoricheskie issledovaniya: [sajt]. - 2020. - № 2. - URL: https://cyberleninka.ru/article/n/stanovlenie-printsipa-dobrosovestnosti-v-otechestvennomgrazhdanskom-prave-istoricheskiy-doktrinalnyy-i-pravoprimenitelnyy-aspekty (data obrashcheniya: 11.04.2021).

8. Solomin S. K. Princip dobrosovestnosti: predely realizacii / pod obshch. red. D. L. Cybakovoj // Grazhdansko-pravovoe regulirovanie obshchestvennyh otnoshenij v sovremennoj Rossii: mat. 7-j mezhdunar. nauchno-prakticheskoj konferencii. Srednerusskij institut upravleniya - filial RANHiGS. - Oryol, 2017. - S. 31-33.

9. Grazhdansko-pravovoe regulirovanie obshchestvennyh otnoshenij v sovremennoj Rossii: sbornik nauchnyh statej / pod red. D. L. Cybakovoj. - Oryol: Izd-vo RANHiGS, 2018. Vyp. 1. - 192 s.

(C) М.В. Вронская, 2021

(C) Е.О. Василенко, 2021

Для цитирования: Вронская М.В., Василенко Е. О. Назначение и функции презумпции добросовестности участников предпринимательских правоотношений // Территория новых возможностей. Вестник Владивостокского государственного университета экономики и сервиса. - 2021. - Т. 13, № 4. - С. 148-155.

For citation: Vronskaya M. V., Vasilenko E. O. The concept and functions of the presumption of good faith of participants in entrepreneurial legal relations, The Territory of New Opportunities. The Herald of Vladivostok State University of Economics and Service, 2021, Vol. 13, № 4, pp. 148-155.

DOI https://doi.org/10.24866/VVSU/2073-3984/2021-4/148-155

$\begin{array}{lll}\text { Дата поступления: } & \text { Одобрена после рецензирования: } & \text { Принята к публикации: } \\ \text { 12.11.2021 } & \text { 19.11.2021 }\end{array}$

